\title{
Pressure-Controlled Ventilation-Volume Guaranteed Mode Combined with an Open-Lung Approach Improves Lung Mechanics, Oxygenation Parameters, and the Inflammatory Response during One-Lung Ventilation: A Randomized Controlled Trial
}

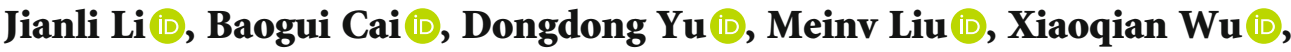 \\ and Junfang Rong $\mathbb{B}$
}

Department of Anesthesiology, Hebei General Hospital, Shijiazhuang 050051, China

Correspondence should be addressed to Jianli Li; hblijianli@163.com

Received 25 December 2019; Revised 27 March 2020; Accepted 28 March 2020; Published 29 April 2020

Academic Editor: Jürgen Bünger

Copyright (C) 2020 Jianli Li et al. This is an open access article distributed under the Creative Commons Attribution License, which permits unrestricted use, distribution, and reproduction in any medium, provided the original work is properly cited.

\begin{abstract}
We evaluated the effectiveness of pressure-controlled ventilation-volume guaranteed (PCV-VG) mode combined with open-lung approach (OLA) in patients during one-lung ventilation (OLV). First, 176 patients undergoing thoracoscopic surgery were allocated randomly to four groups: PCV+OLA (45 cases, PCV-VG mode plus OLA involving application of individualized positive end-expiratory pressure (PEEP) after a recruitment maneuver), PCV (44 cases, PCV-VG mode plus standard lungprotective ventilation with fixed PEEP of $5 \mathrm{cmH}_{2} \mathrm{O}$ ), VCV+OLA (45 cases, volume-controlled ventilation (VCV) plus OLA), and VCV (42 cases, VCV plus standard lung-protective ventilation). Mean airway pressure $\left(P_{\text {mean }}\right)$, dynamic compliance (Cdyn), $\mathrm{PaO}_{2} / \mathrm{FiO}_{2}$ ratio, intrapulmonary shunt ratio (Qs/Qt), dead space fraction $\left(V_{\mathrm{D}} / V_{\mathrm{T}}\right)$, and plasma concentration of neutrophil elastase were obtained to assess the effects of four lung-protective ventilation strategies. At $45 \mathrm{~min}$ after OLV, the median (interquartile range (IQR)) $P_{\text {mean }}$ was higher in the PCV+OLA group $\left(13.00(12.00,13.00) \mathrm{cmH}_{2} \mathrm{O}\right)$ and the VCV +OLA group $\left(12.00(12.00,14.00) \mathrm{cmH}_{2} \mathrm{O}\right)$ than in the PCV group $\left(11.00(10.00,12.00) \mathrm{cmH}_{2} \mathrm{O}\right)$ and the VCV group (11.00 $\left.(10.00,12.00) \mathrm{cmH}_{2} \mathrm{O}\right)(P<0.05)$; the median (IQR) Cdyn was higher in the PCV+OLA group (27.00 (24.00, 32.00) $\left.\mathrm{mL} / \mathrm{cmH}_{2} \mathrm{O}\right)$ and the VCV+OLA group $\left(27.00(22.00,30.00) \mathrm{mL} / \mathrm{cmH}_{2} \mathrm{O}\right)$ than in the PCV group $(23.00(21.00,25.00)$ $\left.\mathrm{mL} / \mathrm{cmH}_{2} \mathrm{O}\right)$ and the VCV group $\left(20.00(18.75,21.00) \mathrm{mL} / \mathrm{cmH}_{2} \mathrm{O}\right)(P<0.05)$; the median (IQR) Qs/Qt in the PCV+OLA group $(0.17(0.16,0.19))$ was significantly lower than that in the PCV group $(0.19(0.18,0.20))$ and the VCV group (0.19 $(0.17,0.20))(P<0.05) ; V_{\mathrm{D}} / V_{\mathrm{T}}$ was lower in the PCV+OLA group $(0.18 \pm 0.05)$ and the VCV+OLA group $(0.19 \pm 0.07)$ than in the PCV group $(0.21 \pm 0.07)$ and the VCV group $(0.22 \pm 0.06)(P<0.05)$. The concentration of neutrophil elastase was lower in the PCV+OLA group than in the PCV, VCV+OLA, and VCV groups at total-lung ventilation $10 \mathrm{~min}$ after OLV $(162.47 \pm 25.71,198.58 \pm 41.99,200.84 \pm 22.17$, and $286.95 \pm 21.10 \mathrm{ng} / \mathrm{mL}$, resp. $)(P<0.05)$. In conclusion, PCV-VG mode combined with an OLA strategy leads to favorable effects upon lung mechanics, oxygenation parameters, and the inflammatory response during OLV.
\end{abstract}

\section{Introduction}

One-lung ventilation (OLV) has been used routinely in thoracic surgery to provide an optimal visual field for a surgical procedure on a collapsed lung. Unfortunately, this approach creates a "shunt-like" effect through the nondependent lung and results in hypoxemia [1]. Furthermore, OLV and surgical trauma are accompanied by the release of excessive amounts 
of inflammatory mediators and neutrophil elastase, which lead to pulmonary infection and systemic inflammatory response syndrome $[2,3]$.

Lung-protective ventilation, consisting a tidal volume $\left(V_{\mathrm{T}}\right)$ of $5-6 \mathrm{~mL} / \mathrm{kg}$ of predicted body weight (PBW) and positive end-expiratory pressure (PEEP) of $5 \mathrm{cmH}_{2} \mathrm{O}$ with an alveoli recruitment maneuver at $20 \mathrm{cmH}_{2} \mathrm{O}$ for $15-20 \mathrm{~s}$, can reduce the risk of ventilator-induced lung injury [4]. However, except for low $V_{\mathrm{T}}$, the advantages of appropriate PEEP with or without an alveoli recruitment maneuver have not been established exactly $[5,6]$. Alternatively, an open-lung approach (OLA), in which the individualized PEEP is determined by PEEP titration after an alveoli recruitment maneuver, can contribute to favorable physiologic effects $[7,8]$.

The literature regarding the ideal ventilation mode on pulmonary outcomes for OLV is controversial [9-11]. Volume-controlled ventilation (VCV) ensures a stable minute ventilation volume, but this mode generates a high airway pressure with subsequent volutrauma and barotrauma and leads to uneven distribution of gas in the lungs. Pressurecontrolled ventilation (PCV) offers the benefits of lower airway pressure with a decelerating flow pattern, but it can provoke lung injury due to a tractive force on alveoli [12]. Pressure-controlled ventilation-volume guaranteed (PCV-VG) mode is a relatively innovative ventilation model introduced to the operating theatre. In PCV-VG mode, initially a preset $V_{\mathrm{T}}$ is transmitted at a lower airway pressure by a decelerating flow. Upon calculation of a patient's pulmonary compliance and inspiratory pressure, the ventilator automatically adjusts the airway pressure of the next breath according to the previous breath's measured exhaled $V_{\mathrm{T}}$ $[13,14]$. Recently, different results by comparing the efficacy of PCV-VG over other modes were published $[9,14]$. Nevertheless, lung-protective ventilation applied to PCV-VG mode has not been studied deeply, and whether PCV-VG combined with an OLA is superior to VCV plus standard lungprotective ventilation during OLV is not known.

We carried out the study to explore the benefits of PCV-VG mode in combination with an OLA on lung mechanics, oxygenation parameters, and the inflammatory response during thoracic surgery.

\section{Materials and Methods}

2.1. Study Population. The ethics committee of Hebei General Hospital (Hebei, China) approved the study protocol. Each participant (or family member) provided written informed consent. The study was registered with the Chinese Clinical Trial Registry (ChiCTR1900020895).

The study enrolled patients with ASA physical status I-III scheduled for elective thoracoscopic surgery requiring OLV. Patients were excluded if they met any of the following criteria: age $<18$ years, body mass index $\geq 35 \mathrm{~kg} / \mathrm{m}^{2}$, pneumothorax or giant bullae, chronic lung disease or pulmonary infection within one month of study initiation, previous thoracic surgery, and contraindication to PEEP (high intracranial pressure, hypovolemic shock, or rightheart failure). Dropout criteria were a change in type of surgical procedure to thoracotomy, intraoperative bleeding $\geq 500 \mathrm{~mL}$, and OLV duration $<45 \mathrm{~min}$.

2.2. Randomization. Participants were assigned to one of four lung-protective ventilation strategies using a computergenerated randomization sequence, with an allocation of $1: 1: 1: 1$.

2.3. Anesthesia and Surgery. After placement of monitors, anesthesia induction and endobronchial intubation were achieved with $0.3 \mathrm{mg} / \mathrm{kg}$ etomidate, $0.3 \mu \mathrm{g} / \mathrm{kg}$ sufentanil, and $1.0 \mathrm{mg} / \mathrm{kg}$ rocuronium. The location of the left- or right-sided double-lumen tube (DLT) was regulated by a fiberoptic bronchoscope in supine and lateral positions. Anesthesia was maintained with sevoflurane, remifentanil, and rocuronium. Sevoflurane was titrated to keep the bispectral index between 40 and 60. Lactated Ringer's solution was infused continuously at $3-5 \mathrm{~mL} / \mathrm{kg} / \mathrm{h}$. All patients received patient-controlled intravenous analgesia after surgery. And patients were treated in the thoracic surgery intensive care unit (ICU) after surgery.

2.4. General Ventilator Strategy. After endobronchial intubation, all patients in the four groups were ventilated with an anesthesia ventilator (Avance CS ${ }^{2}$ Pro; GE Healthcare, Piscataway, NJ, USA).

Before OLV, all participants were set the same ventilation parameters, consisting of a fraction of inspired oxygen $\left(\mathrm{FiO}_{2}\right)$ of 1.0, $V_{\mathrm{T}}$ of $8 \mathrm{~mL} / \mathrm{kg} \mathrm{PBW}$, and an initial PEEP of $5 \mathrm{cmH}_{2} \mathrm{O}$ (which was maintained in the PCV group and the VCV group throughout the whole procedure).

During OLV, all individuals received a $V_{\mathrm{T}}$ of $5-6 \mathrm{~mL} / \mathrm{kg}$ PBW with $\mathrm{FiO}_{2}$ of 0.8 . The inspiratory : expiratory ( $\left.\mathrm{I}: \mathrm{E}\right)$ ratio was $1: 2$, and ventilation frequency was adjusted to maintain end-tidal carbon dioxide partial pressure $\left(\mathrm{P}_{\mathrm{ET}} \mathrm{CO}_{2}\right)$ between 35 and $45 \mathrm{mmHg}$. The maximal acceptable peak airway pressure $\left(P_{\text {peak }}\right)$ was set at $30 \mathrm{cmH}_{2} \mathrm{O}$, and if $P_{\text {peak }}$ was exceeded, VCV was switched to PCV.

\subsection{Alveoli Recruitment Maneuver and Decremental PEEP} Trial. OLV was initiated after rechecking the correct position of the DLT. The dependent lung had a standard alveoli recruitment maneuver. The ventilation mode was changed from VCV to PCV with a driving pressure of $20 \mathrm{cmH}_{2} \mathrm{O}$ and respiratory rate of 15 breaths per minute, PEEP of $5 \mathrm{cmH}_{2} \mathrm{O}, \mathrm{I}: \mathrm{E}$ of $1: 1$, and $\mathrm{FiO}_{2}$ of 1.0. PEEP was increased at a step size of $5 \mathrm{cmH}_{2} \mathrm{O}$, and 10 breaths were maintained at each step $\left(5,10,15\right.$, and $\left.20 \mathrm{cmH}_{2} \mathrm{O}\right)$ until recruitment of opening pressure up to $40 \mathrm{cmH}_{2} \mathrm{O}\left(20 \mathrm{cmH}_{2} \mathrm{O}\right.$ PEEP and $20 \mathrm{cmH}_{2} \mathrm{O}$ of driving pressure) was applied for 20 breaths.

If the hemodynamics were unstable during the alveoli recruitment maneuver phase (a decrease in mean arterial pressure $(\mathrm{MAP})>30 \%)$, the alveoli recruitment maneuver was interrupted and vasoactive drugs given; after hemodynamic stability, a new alveoli recruitment maneuver was implemented.

After the first alveoli recruitment maneuver had been accomplished, individualized PEEP was titrated through a trial with decreased PEEP. PEEP was reduced in steps of 


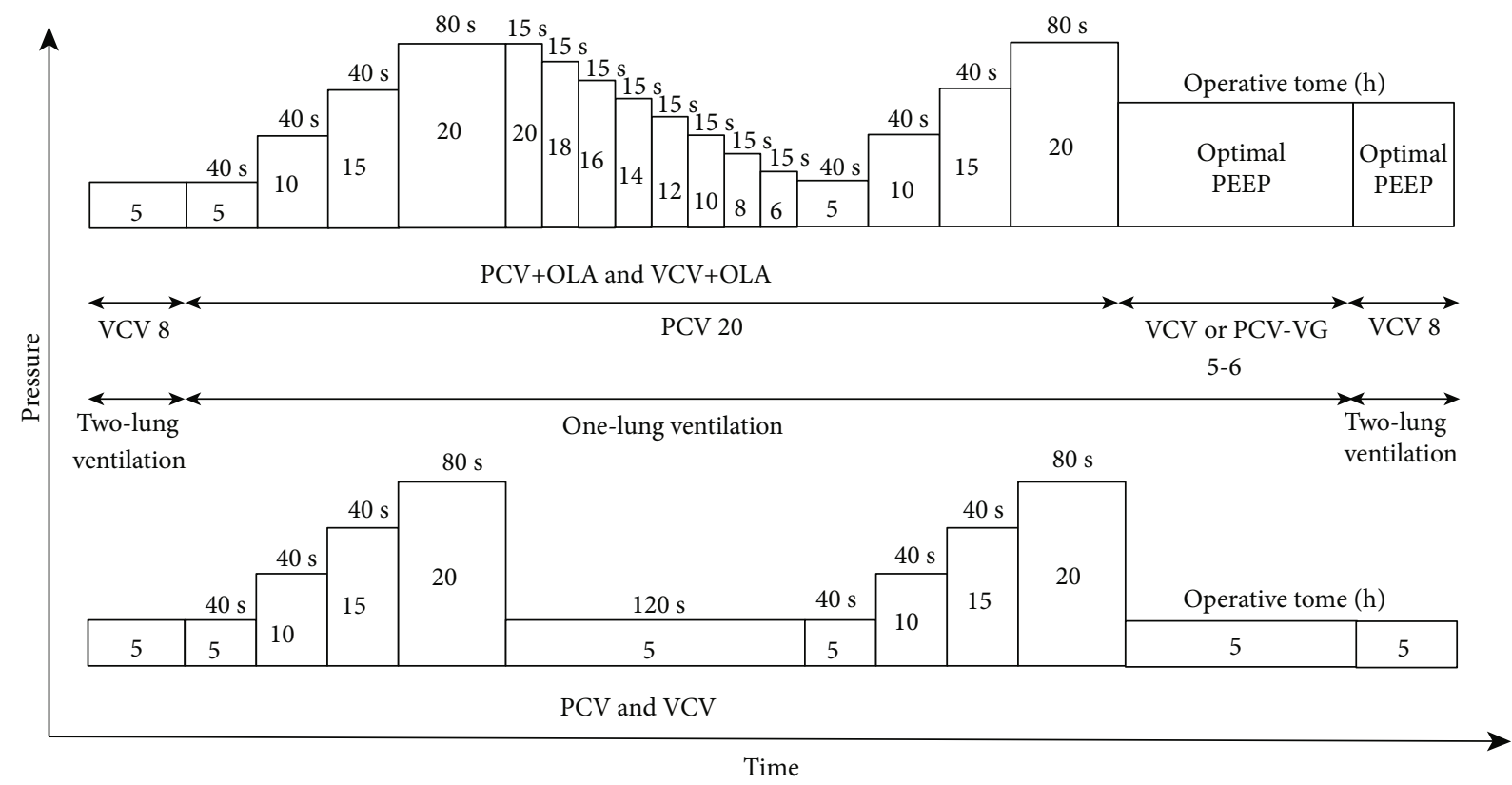

FIGURE 1: PCV 20: pressure-controlled ventilation mode with $20 \mathrm{cmH}_{2} \mathrm{O}$; VCV 8: volume-controlled ventilation mode with tidal volume set to $8 \mathrm{~mL} / \mathrm{kg}$; VCV or PCV-VG 5-6: volume-controlled ventilation mode or pressure-controlled ventilation-volume guaranteed mode with tidal volume set to 5 to $6 \mathrm{~mL} / \mathrm{kg}$.

$2 \mathrm{cmH}_{2} \mathrm{O}$ with each PEEP level $(20,18,16,14,12,10,8$, and $6 \mathrm{cmH}_{2} \mathrm{O}$ ) and held for $15 \mathrm{~s}$ until the greatest dynamic compliance (Cdyn) was produced, which was considered to be the individualized or optimal PEEP. Then, a new alveoli recruitment maneuver was carried out as described above (Figure 1).

2.6. Specific Intraoperative Ventilatory Management. In the PCV+OLA group, after the second alveoli recruitment maneuver, the ventilation mode was changed to PCV-VG during OLV, and the optimal PEEP was established and maintained throughout the whole study period.

In the VCV+OLA group, patients received the same procedures (alveoli recruitment maneuver and trial of decreased PEEP), the ventilation mode was switched to VCV during OLV, and the optimal PEEP maintained throughout the whole study period.

In the PCV and VCV groups, the same procedure (alveoli recruitment maneuver) was followed except for the PEEP titration. Patients received PCV-VG or VCV plus fixed PEEP $\left(5 \mathrm{cmH}_{2} \mathrm{O}\right)$ during OLV, respectively.

It is worth noting that alveoli recruitment maneuver was performed after OLV without PEEP titration. The ventilation mode was changed to VCV, and the PEEP value of each group was consistent with that during OLV.

2.7. Measurements. Studied variables were collected at three time points: (i) $\mathrm{T}_{1}$ : total-lung ventilation $10 \mathrm{~min}$ after intubation; (ii) $\mathrm{T}_{2}$ : OLV for $45 \mathrm{~min}$; and (iii) $\mathrm{T}_{3}$ : total-lung ventilation $10 \mathrm{~min}$ after OLV.

The studied endpoints were partial pressure of arterial carbon dioxide $\left(\mathrm{PaCO}_{2}\right), \mathrm{pH}, V_{\mathrm{T}}, \mathrm{PEEP}$, mean airway pres- sure $\left(P_{\text {mean }}\right)$, Cdyn, $P_{\text {peak }}$, dead space fraction $\left(V_{\mathrm{D}} / V_{\mathrm{T}}\right)$, intrapulmonary shunt ratio (Qs/Qt), arterial partial pressure of oxygen/fraction of inspired oxygen $\left(\mathrm{PaO}_{2} / \mathrm{FiO}_{2}\right.$ ratio), and the plasma concentration of neutrophil elastase.

Parameters were calculated using the following equations:

$V_{D} / V_{T}=\left(\mathrm{PaCO}_{2}-P_{E T} \mathrm{CO}_{2}\right) / \mathrm{PaCO}_{2}$

$$
Q s / Q t=\left(P A-a D O_{2} \times 0.0031\right) \div\left(P A-a D O_{2} \times 0.0031+5\right)
$$

whereby $\mathrm{PA}-\mathrm{aDO}_{2}=\left[\mathrm{FiO}_{2} \times\left(P_{\mathrm{B}}-P_{\mathrm{H} 2 \mathrm{O}}\right)\right]-\left(\mathrm{PaCO}_{2} / R\right)-$ $\mathrm{PaO}_{2}$.

$\mathrm{PA}-\mathrm{aDO}_{2}$ is the alveolar-arterial oxygen difference; $P_{\mathrm{B}}$ is the barometric pressure $(760 \mathrm{mmHg}) ; P_{\mathrm{H} 2 \mathrm{O}}$ is the vapor pressure of water $(47 \mathrm{mmHg}) ; R$ is the respiratory quotient $(0.8)$.

The plasma concentration of neutrophil elastase was measured by enzyme-linked immunosorbent assays at $T_{1}$ and $\mathrm{T}_{3}$.

Postoperative endpoints in the four groups were recorded: prevalence of pneumonia, atelectasis, and acute respiratory failure; duration of ICU stay; and duration of hospital stay after surgery.

\section{Statistical Analyses}

The sample size for our study was determined according to a pilot study, with an $\alpha$ level of 0.05 , power of 0.8 , and effect size of 0.3 . Assuming a dropout of $30 \%$ of cases, 200 patients (50 patients per group) were included in each group. 


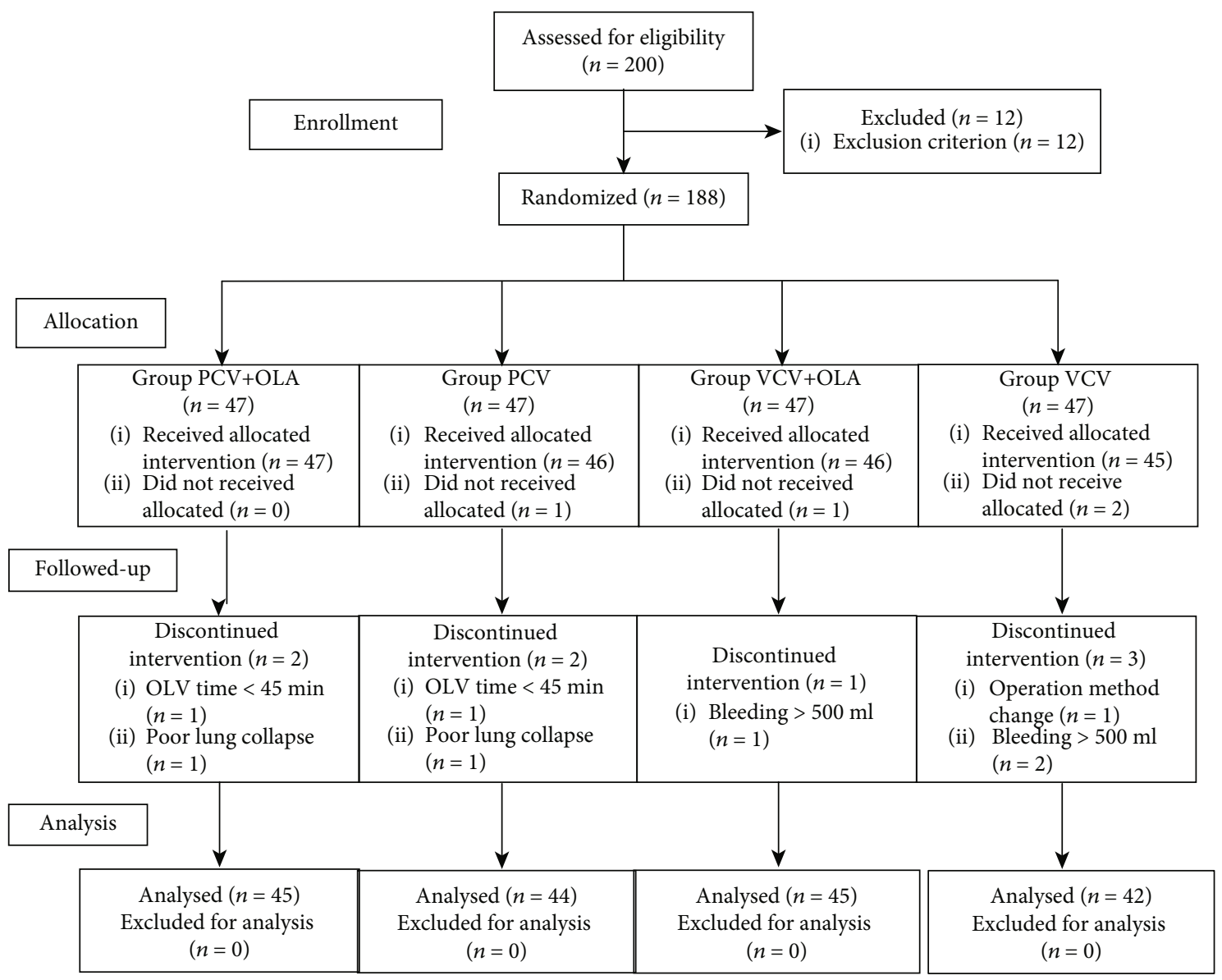

FIgure 2: The study flow diagram.

Statistical data were analyzed using SPSS 22.0 (IBM, Armonk, NY, USA). The Shapiro-Wilk test was used for data with a normal distribution. Continuous variables are given as the mean \pm standard deviation (SD) or median (interquartile range (IQR)). Categorical variables are described as numbers. Categorical data were analyzed using the chi-squared test. Data with a normal distribution were compared among the four groups using one-way ANOVA with LSD-t as the post hoc test. The Kruskal-Wallis test was used to compare multiple groups on continuous variables with a nonnormal distribution. $P<0.05$ (two-sided) was considered significant for all tests.

\section{Results}

4.1. Demographic and Intraoperative Characteristics of Patients. Initially, 200 patients were assessed for eligibility, and 176 patients completed the study (Figure 2). The four groups were balanced in terms of demographics and data relating to the surgical procedure $(P>0.05)$ (Tables 1 and 2$)$.

4.2. Mechanics of the Respiratory System. Compared with the PCV and VCV groups (both $5.00 \mathrm{cmH}_{2} \mathrm{O}$ ), the median (IQR) PEEP was higher in the PCV+OLA group $(8.00(8.00,10.00)$ $\left.\mathrm{cmH}_{2} \mathrm{O}\right)$ and the VCV+OLA group $(10.00(8.00,12.00)$ $\left.\mathrm{cmH}_{2} \mathrm{O}\right)(P<0.001)$.
At $\mathrm{T}_{2}$, the median (IQR) $P_{\text {mean }}$ was higher in the PCV+ OLA group $\left(13.00(12.00,13.00) \mathrm{cmH}_{2} \mathrm{O}\right)$ and the VCV+ OLA group $\left(12.00(12.00,14.00) \mathrm{cmH}_{2} \mathrm{O}\right)$ than in the PCV and VCV groups (both $11.00(10.00,12.00) \mathrm{cmH}_{2} \mathrm{O}$ ) $(P<0.05)$. The median (IQR) Cdyn was higher in the PCV+OLA group $\left(27.00(24.00,32.00) \mathrm{mL} / \mathrm{cmH}_{2} \mathrm{O}\right)$ and the VCV+OLA group $\left(27(22.00,30.00) \mathrm{mL} / \mathrm{cmH}_{2} \mathrm{O}\right)$ than in the PCV group $\left(23.00(21.00,25.00) \mathrm{mL} / \mathrm{cmH}_{2} \mathrm{O}\right)$ and the VCV group $\left(20.00(18.75,21.00) \mathrm{mL} / \mathrm{cmH}_{2} \mathrm{O}\right)$ at $\mathrm{T}_{2}$ $(P<0.05)$. At $\mathrm{T}_{2}, P_{\text {peak }}$ showed no difference in the PCV+OLA and PCV groups $(P=0.320)$ or the VCV+OLA and VCV groups $(P=0.856)$ (Table 3$)$.

4.3. Variables in Ventilation Efficiency. At $\mathrm{T}_{2}$, the median (IQR) Qs/Qt in the PCV+OLA group $(0.17(0.16,0.19))$ was significantly lower than that in the PCV group $(0.19$ $(0.18,0.20))$ and the VCV group $(0.19(0.17,0.20))$ $(P<0.05) . \quad V_{\mathrm{D}} / V_{\mathrm{T}}$ was lower in the PCV+OLA group $(0.18 \pm 0.05)$ and the VCV+OLA group $(0.19 \pm 0.07)$ than that in the PCV group $(0.21 \pm 0.07)$ and the VCV group $(0.22 \pm 0.06)$ at $\mathrm{T}_{2}(P<0.05)$. Compared with the VCV group, the $\mathrm{PaO}_{2} / \mathrm{FiO}_{2}$ ratio increased in the PCV+OLA and VCV+OLA groups (median (IQR) $173.75(138.13,221.87)$ vs. $134.38(106.25,180.63) ; 166.25(146.25,200.63)$ vs. 134.38 (106.25, 180.63), $P<0.05)$ (Table 3$).$ 


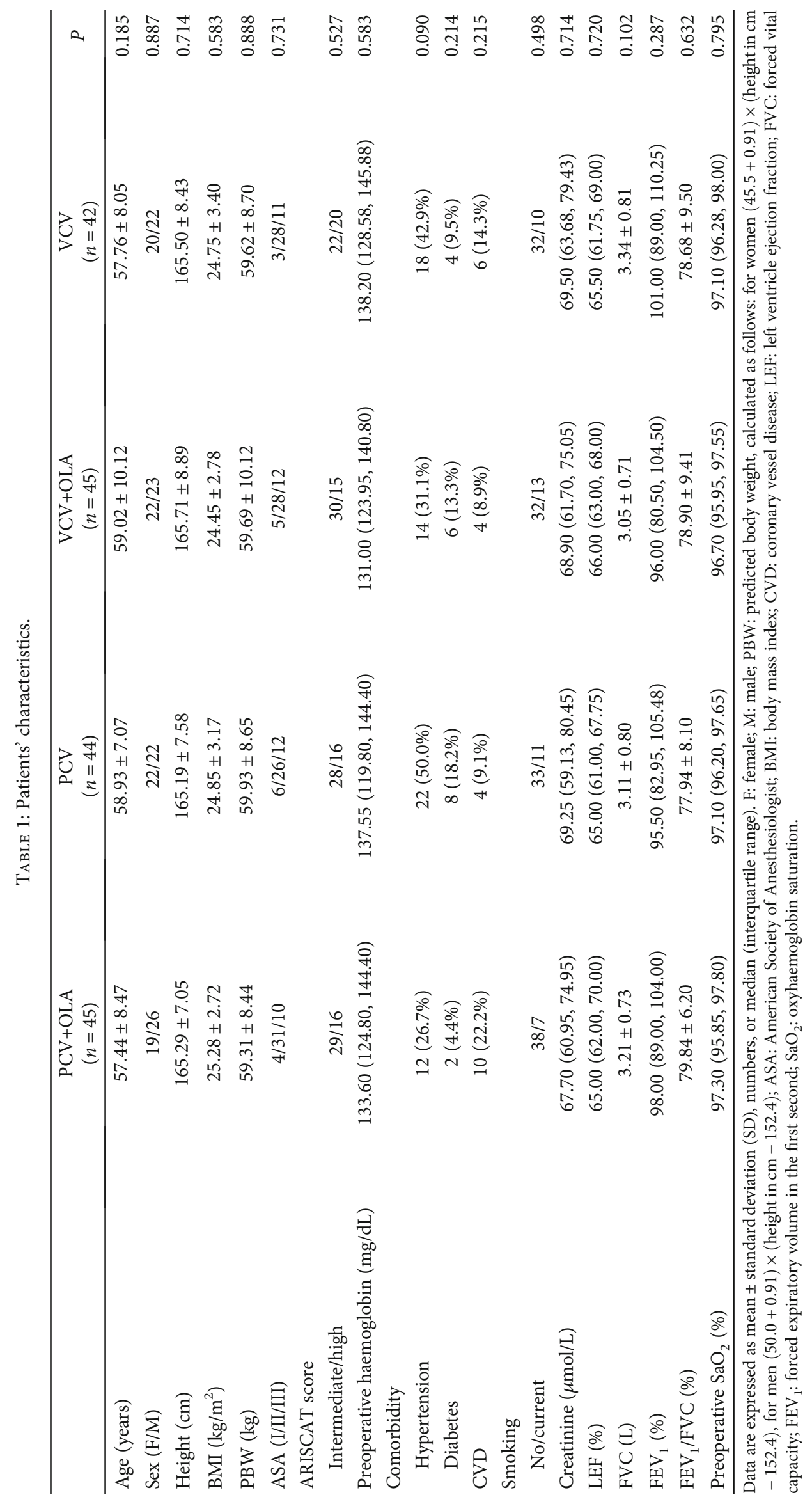




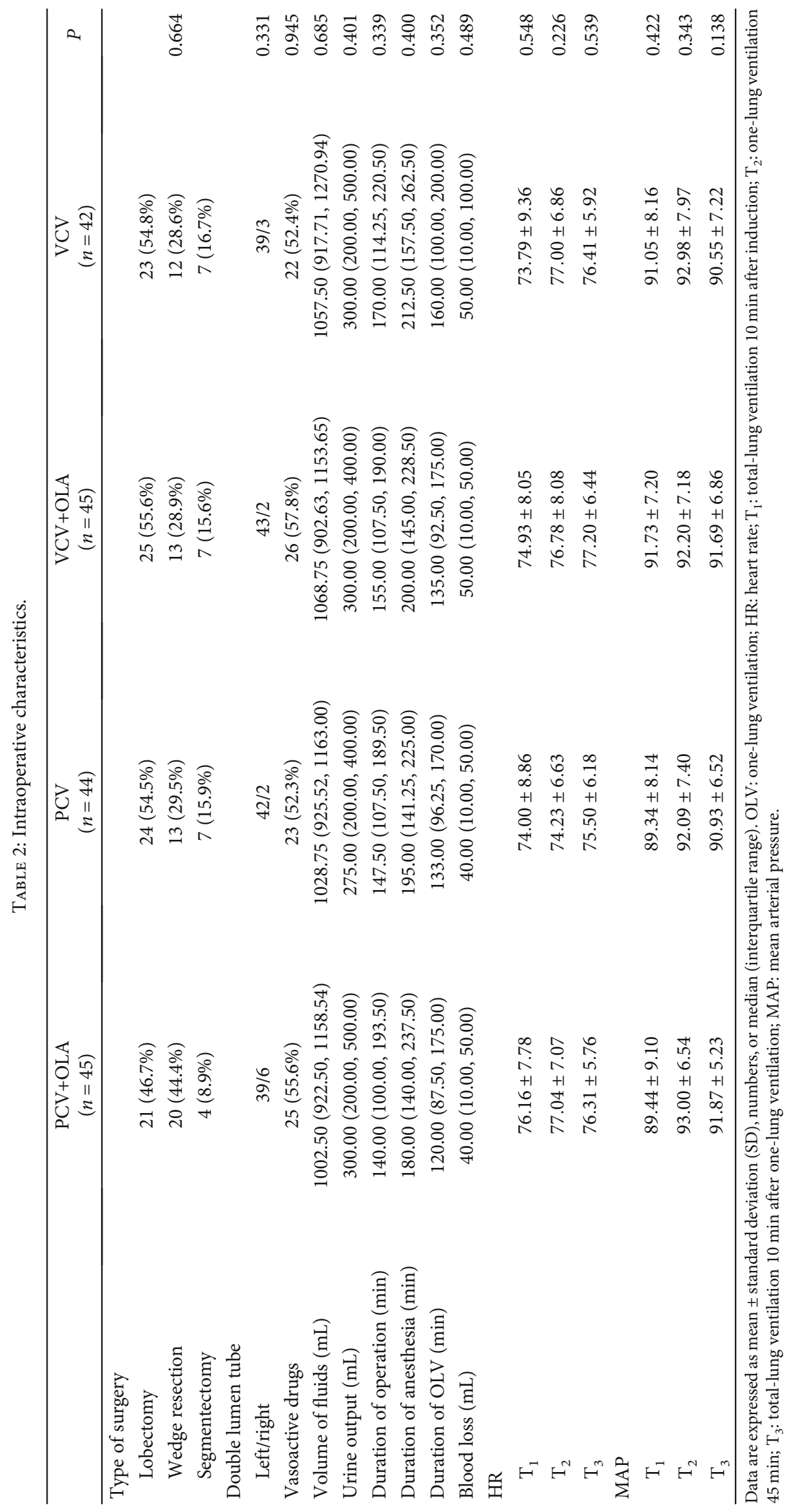


TABLE 3: Ventilatory parameters, respiratory system mechanics, blood gas, and oxygenation parameters.

\begin{tabular}{|c|c|c|c|c|c|}
\hline & $\begin{array}{c}\mathrm{PCV}+\mathrm{OLA} \\
(n=45)\end{array}$ & $\begin{array}{c}\text { PCV } \\
(n=44)\end{array}$ & $\begin{array}{c}\mathrm{VCV}+\mathrm{OLA} \\
(n=45)\end{array}$ & $\begin{array}{c}\text { VCV } \\
(n=42)\end{array}$ & $P$ \\
\hline \multicolumn{6}{|c|}{$V_{\mathrm{T}}(\mathrm{mL})$} \\
\hline $\mathrm{T}_{1}$ & $432.00(405.00,475.00)$ & $429.50(404.50,499.75)$ & $445.00(399.50,502.00)$ & $449.50(410.25,503.25)$ & 0.841 \\
\hline $\mathrm{T}_{2}$ & $314.09 \pm 34.35$ & $324.98 \pm 39.64$ & $318.29 \pm 47.47$ & $326.90 \pm 44.93$ & 0.451 \\
\hline $\mathrm{T}_{3}$ & $431.00(408.00,500.50)$ & $442.50(411.50,502.00)$ & $452.00(405.00,503.00)$ & $441.00(407.00,507.25)$ & 0.936 \\
\hline \multicolumn{6}{|c|}{$\operatorname{PEEP}\left(\mathrm{cmH}_{2} \mathrm{O}\right)$} \\
\hline $\mathrm{T}_{1}$ & 5.00 & 5.00 & 5.00 & 5.00 & - \\
\hline $\mathrm{T}_{2}$ & $8.00(8.00,10.00)^{* \boldsymbol{\Lambda}}$ & 5.00 & $10.00(8.00,12.00)^{* \boldsymbol{\Delta}}$ & 5.00 & $<0.001$ \\
\hline $\mathrm{T}_{3}$ & $8.00(8.00,10.00)^{* \boldsymbol{\Lambda}}$ & 5.00 & $10.00(8.00,12.00)^{*} \boldsymbol{\Delta}$ & 5.00 & $<0.001$ \\
\hline \multicolumn{6}{|c|}{$P_{\text {peak }(}\left(\mathrm{cmH}_{2} \mathrm{O}\right)$} \\
\hline $\mathrm{T}_{1}$ & $18.71 \pm 2.62$ & $17.93 \pm 2.98$ & $19.16 \pm 2.43$ & $18.64 \pm 3.45$ & 0.255 \\
\hline $\mathrm{T}_{2}$ & $21.00(20.00,22.00)^{\triangle \boldsymbol{\Lambda}}$ & $22.00(19.25,23.00)^{\triangle \boldsymbol{\Lambda}}$ & $24.00(23.00,25.00)$ & $23.00(21.00,25.00)$ & $<0.001$ \\
\hline $\mathrm{T}_{3}$ & $20.22 \pm 2.39$ & $18.82 \pm 2.95 \triangle$ & $21.84 \pm 2.49$ & $18.69 \pm 4.69 \triangle$ & $<0.001$ \\
\hline \multicolumn{6}{|c|}{$P_{\text {mean }(}\left(\mathrm{cmH}_{2} \mathrm{O}\right)$} \\
\hline $\mathrm{T}_{1}$ & $10.00(9.00,11.00)$ & $10.00(9.00,11.00)$ & $10.00(9.00,11.00)$ & $10.00(9.00,11.00)$ & 0.245 \\
\hline $\mathrm{T}_{2}$ & $13.00(12.00,13.00)^{* \boldsymbol{\Lambda}}$ & $11.00(10.00,12.00)$ & $12.00(12.00,14.00)^{* \boldsymbol{\Lambda}}$ & $11.00(10.00,12.00)$ & $<0.001$ \\
\hline $\mathrm{T}_{3}$ & $12.00(11.00,13.00)^{* \boldsymbol{\Lambda}}$ & $11.00(10.00,12.00)$ & $12.00(11.00,13.00)^{* \boldsymbol{\Lambda}}$ & $10.00(8.00,11.00)$ & $<0.001$ \\
\hline \multicolumn{6}{|c|}{ Cdyn $\left(\mathrm{mL} / \mathrm{cmH}_{2} \mathrm{O}\right)$} \\
\hline $\mathrm{T}_{1}$ & $46.60 \pm 5.60$ & $46.36 \pm 6.57$ & $45.78 \pm 7.51$ & $46.17 \pm 6.25$ & 0.943 \\
\hline $\mathrm{T}_{2}$ & $27.00(24.00,32.00)^{* \boldsymbol{\Lambda}}$ & $23.00(21.00,25.00)$ & $27.00(22.00,30.00)^{* \boldsymbol{\Lambda}}$ & $20.00(18.75,21.00)$ & $<0.001$ \\
\hline $\mathrm{T}_{3}$ & $47.33 \pm 5.59^{*} \boldsymbol{\triangle}$ & $44.78 \pm 4.25^{\wedge}$ & $46.18 \pm 5.22^{\wedge}$ & $43.12 \pm 5.20$ & 0.001 \\
\hline \multicolumn{6}{|c|}{$\mathrm{PaCO}_{2}(\mathrm{mmHg})$} \\
\hline $\mathrm{T}_{1}$ & $42.29 \pm 3.76$ & $43.30 \pm 3.76$ & $43.78 \pm 4.38$ & $43.57 \pm 4.77$ & 0.345 \\
\hline $\mathrm{T}_{2}$ & $44.43 \pm 3.90$ & $44.17 \pm 4.89$ & $45.26 \pm 4.71$ & $44.20 \pm 4.81$ & 0.485 \\
\hline $\mathrm{T}_{3}$ & $43.00(39.50,47.00)$ & $45.00(41.00,47.00)$ & $46.00(41.00,48.00)$ & $44.00(41.00,47.25)$ & 0.455 \\
\hline \multicolumn{6}{|l|}{$\mathrm{pH}$} \\
\hline $\mathrm{T}_{1}$ & $7.40 \pm 0.03$ & $7.39 \pm 0.03$ & $7.39 \pm 0.04$ & $7.39 \pm 0.04$ & 0.402 \\
\hline $\mathrm{T}_{2}$ & $7.38(7.35,7.40)$ & $7.38(7.35,7.42)$ & $7.37(7.39,7.40)$ & $7.38(7.35,7.41)$ & 0.633 \\
\hline $\mathrm{T}_{3}$ & $7.38 \pm 0.04$ & $7.38 \pm 0.03$ & $7.38 \pm 0.05$ & $7.38 \pm 0.04$ & 0.796 \\
\hline \multicolumn{6}{|c|}{$V_{\mathrm{D}} / V_{\mathrm{T}}$} \\
\hline $\mathrm{T}_{1}$ & $0.17 \pm 0.04$ & $0.18 \pm 0.06$ & $0.19 \pm 0.06$ & $0.19 \pm 0.05$ & 0.210 \\
\hline $\mathrm{T}_{2}$ & $0.18 \pm 0.05^{*} \boldsymbol{\Lambda}$ & $0.21 \pm 0.07$ & $0.19 \pm 0.07^{*} \boldsymbol{\Lambda}$ & $0.22 \pm 0.06$ & 0.003 \\
\hline $\mathrm{T}_{3}$ & $0.16(0.13,0.21)^{* \boldsymbol{\Lambda}}$ & $0.20(0.17,0.24)$ & $0.19(0.14,0.22)$ & $0.21(0.17,0.24)$ & $<0.001$ \\
\hline \multicolumn{6}{|c|}{ Qs/Qt } \\
\hline $\mathrm{T}_{1}$ & $0.16 \pm 0.03$ & $0.16 \pm 0.03$ & $0.16 \pm 0.04$ & $0.16 \pm 0.03$ & 0.873 \\
\hline $\mathrm{T}_{2}$ & $0.17(0.16,0.19)^{* \boldsymbol{\Lambda}}$ & $0.19(0.18,0.20)$ & $0.18(0.17,0.19)$ & $0.19(0.17,0.20)$ & 0.006 \\
\hline $\mathrm{T}_{3}$ & $0.17 \pm 0.03$ & $0.17 \pm 0.03$ & $0.17 \pm 0.03$ & $0.18 \pm 0.03$ & 0.280 \\
\hline \multicolumn{6}{|c|}{$\mathrm{PaO}_{2} / \mathrm{FiO}_{2}$ ratio } \\
\hline $\mathrm{T}_{1}$ & $341.91 \pm 78.37$ & $350.95 \pm 62.70$ & $342.47 \pm 81.27$ & $352.10 \pm 74.73$ & 0.875 \\
\hline $\mathrm{T}_{2}$ & $173.75(138.13,221.87)^{\mathbf{\Lambda}}$ & $153.13(109.38,185.94)$ & $166.25(146.25,200.63)^{\mathbf{\Lambda}}$ & $134.38(106.25,180.63)$ & 0.002 \\
\hline $\mathrm{T}_{3}$ & $330.69 \pm 65.24$ & $327.40 \pm 64.31$ & $317.60 \pm 65.71$ & $304.12 \pm 73.40$ & 0.264 \\
\hline
\end{tabular}

Data are expressed as mean \pm standard deviation (SD) or median (interquartile range). $V_{\mathrm{T}}$ : tidal volume; $\mathrm{T}_{1}$ : total-lung ventilation 10 min after induction; $\mathrm{T}_{2}$ : one-lung ventilation $45 \mathrm{~min} ; \mathrm{T}_{3}$ : total-lung ventilation $10 \mathrm{~min}$ after one-lung ventilation; PEEP: positive end-expiratory pressure; $P_{\text {peak }}$ : peak airway pressure; $P_{\text {mean }}$ : mean airway pressure; Cdyn: dynamic compliance; $\mathrm{PaCO}_{2}$ : partial pressure of arterial carbon dioxide; $V_{\mathrm{D}} / V_{\mathrm{T}}$ : dead space fraction; Qs/Qt: intrapulmonary shunt ratio; $\mathrm{PaO}_{2} / \mathrm{FiO}_{2}$ : arterial partial pressure of oxygen/fraction of inspired oxygen. ${ }^{*} \mathrm{P}<0.05$ versus $\mathrm{PCV},{ }^{\triangle} \mathrm{P}<0.05$ versus VCV+OLA, and ${ }^{\mathbf{\Delta}} P<0.05$ versus VCV. 


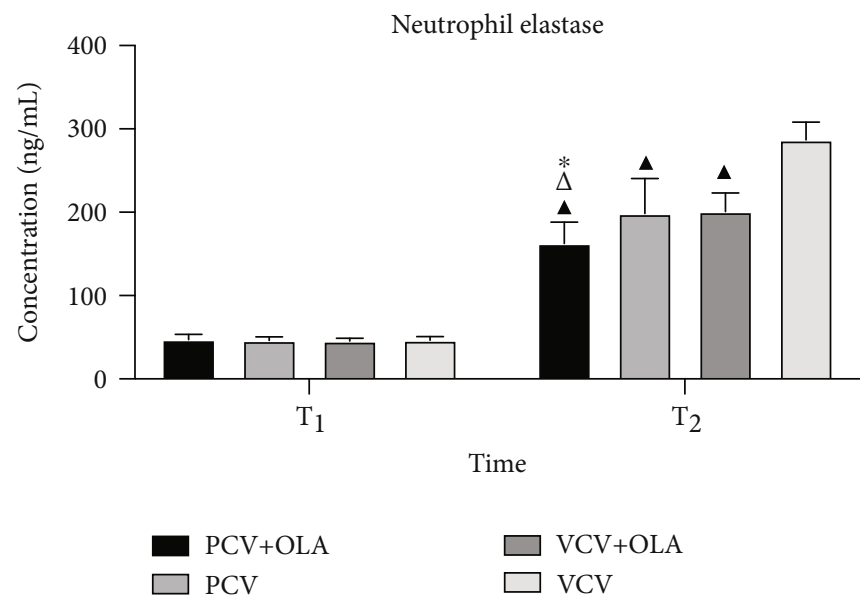

FIgURE 3: The plasma concentration of neutrophil elastase. Data are expressed as mean \pm standard deviation (SD). ${ }^{*} P<0.05$ versus $P C V$, ${ }^{\triangle} P<0.05$ versus $\mathrm{VCV}+\mathrm{OLA}$, and $\boldsymbol{\Delta}^{\mathrm{P}}<0.05$ versus $\mathrm{VCV}$.

TABLE 4: Other clinical endpoints.

\begin{tabular}{|c|c|c|c|c|c|}
\hline & $\begin{array}{c}\text { PCV+OLA } \\
(n=45)\end{array}$ & $\begin{array}{c}\mathrm{PCV} \\
(n=44)\end{array}$ & $\begin{array}{c}\mathrm{VCV}+\mathrm{OLA} \\
(n=45)\end{array}$ & $\begin{array}{c}\text { VCV } \\
(n=42)\end{array}$ & $P$ \\
\hline Pneumonia & $2(4.4 \%)$ & $5(11.4 \%)$ & $4(8.9 \%)$ & $7(16.7 \%)$ & 0.312 \\
\hline Atelectasis & $1(2.2 \%)$ & $4(9.1 \%)$ & $2(4.4 \%)$ & $6(14.3 \%)$ & 0.148 \\
\hline Acute respiratory failure & $0(0 \%)$ & $1(2.3 \%)$ & $1(2.2 \%)$ & $4(9.5 \%)$ & 0.096 \\
\hline The duration of ICU stay (hours) & $32.00(25.00,37.00)^{* \triangle \boldsymbol{\Lambda}}$ & $39.75(32.88,43.00)$ & $39.50(27.00,43.50)$ & $39.60(24.88,43.70)$ & $<0.001$ \\
\hline $\begin{array}{l}\text { The duration of hospital stay after } \\
\text { surgery (days) }\end{array}$ & $6.00(5.00,7.00)$ & $6.00(5.00,8.00)$ & $6.00(5.00,8.00)$ & $6.00(4.75,7.00)$ & 0.204 \\
\hline
\end{tabular}

Data are expressed as median (interquartile range) or numbers. ICU: intensive care unit. ${ }^{*} P<0.05$ versus PCV, ${ }^{\triangle} P<0.05$ versus VCV+OLA, and ${ }^{\Delta} P<0.05$ versus VCV.

4.4. Plasma Concentration of Neutrophil Elastase. There was no significant difference in the plasma neutrophil elastase level among the four groups at $\mathrm{T}_{1} \quad(P>0.05)$. The plasma concentration of neutrophil elastase was lower in the PCV+OLA group than that in the PCV, $\mathrm{VCV}+\mathrm{OLA}$, and VCV groups at $\mathrm{T}_{3} \quad(162.47 \pm 25.71$, $198.58 \pm 41.99,200.84 \pm 22.17$, and $286.95 \pm 21.10, \mathrm{ng} / \mathrm{mL}$, resp.) $(P<0.05)$ (Figure 3$)$.

4.5. Other Clinical Endpoints. The duration of ICU stay in the $\mathrm{PCV}+\mathrm{OLA}$ group was shorter compared with that in PCV, $\mathrm{VCV}+\mathrm{OLA}$, and VCV groups (median (IQR) 32.00 (25.00, $37.00), 39.75(32.88,43.00), 39.50(27.00,43.50)$, and 39.60 $(24.88,43.70) \mathrm{h}$, resp.) $(P<0.05)$. There were no significant differences in the duration of hospital stay and the prevalence of pneumonia, atelectasis, and acute respiratory failure in the four groups after surgery $(P>0.05)$ (Table 4$)$.

\section{Discussion}

The randomized controlled trial revealed that the ventilation strategy of PCV-VG plus OLA during OLV leads to preferable levels of $\mathrm{Cdyn}, \mathrm{PaO}_{2} / \mathrm{FiO}_{2}$ ratio, and appropriate levels of $P_{\text {mean }}, V_{\mathrm{D}} / V_{\mathrm{T}}, \mathrm{Qs} / \mathrm{Qt}$, and neutrophil elastase. Additionally, the duration of ICU stay was shorter in the PCV+OLA group compared with the other three groups. These results suggest that the ventilation strategy of PCV-VG combined with OLA during OLV is beneficial for patients undergoing thoracic surgery.

Patients undergoing OLV are susceptible to hypoxemia due to shunting of blood or imbalance of ventilation and pulmonary perfusion. And the practice of OLV is an independent hazard factor for postoperative pulmonary complications (PPCs), as a result of direct surgical trauma of the nonventilated lung, exposed to high strain and nonphysiologic $V_{\mathrm{T}}$ of the ventilated lung $[15,16]$. Multiple mechanisms can cause lung tissue damage and inflammatory cytokine release, which often ahead of pneumonia and systemic inflammatory response syndrome ultimately affect the clinical prognosis of patients undergoing thoracic surgery $[17,18]$.

Usually, the lung-protective ventilation strategy, which has taken low $V_{\mathrm{T}}$ as the core, is accepted by anesthesiologists as an effective way to alleviate ventilator-induced lung injury [19]. However, the application of a low $V_{\mathrm{T}}$ without sufficient PEEP may be relevant to cyclic alveolar derecruitment with consequent promote atelectrauma [6]. PEEP can prevent atelectasis effectively, but the optimal PEEP level is not known. Pereira et al. observed that PEEP varied markedly 
among individuals and stated that intraoperative individualized PEEP settings could lower the risk of postoperative atelectasis while improving driving pressure and oxygenation [20]. On the contrary, a study showed that different perioperative OLA with individualized PEEP in major abdominal surgery did not reduce the prevalence of postoperative complications when compared with conventional lung-protective ventilation strategy [21]. Most protective ventilation strategies (including the OLA) were undertaken under VCV mode, which could pose a potential risk of high airway pressure and trigger pulmonary inflammatory response compared with PCV or PCV-VG [10, 22]. The PCV-VG mode has features of PCV and VCV, which creates lower airway pressure than that seen with VCV accompanied with improvement in oxygenation and reduction in the pulmonary shunt $[1,13]$. However, Byun and colleagues indicated that the application of $V_{\mathrm{T}}$ of $6 \mathrm{~mL} / \mathrm{kg}$ with zero PEEP under PCV-VG led to a high risk of intraoperative hypoxemia [23]. Moreover, many studies found that compared with VCV, PCV-VG did not significantly improve intraoperative oxygenation $[24,25]$. Hence, we designed this study to explore the benefits of PCV-VG along with an individualized OLA strategy in patients undergoing lung surgery with OLV.

The results of the present study are consistent with our expectation that using an OLA with individualized PEEP under PCV-VG mode can improve pulmonary gas exchange and lung mechanics as well as hemodynamic stability during OLV. Nevertheless, it is useful to note that during OLV, routinely measured airway pressure does not reflect the bronchial pressure, and the decrease in $P_{\text {peak }}$ under PCV mode is probably not clinically relevant when measured in the bronchus of the ventilated lung [26]. Therefore, we assumed that the difference in $P_{\text {peak }}$ in this study is meaningless due to the ventilation mode-related difference in endinspiratory flow, as well as the resistance of the tracheal tube [27]. Unlike $P_{\text {peak }}$, previous studies have demonstrated that $P_{\text {mean }}$ closely reflects mean alveolar pressure and correlates with alveolar ventilation, arterial oxygenation, hemodynamic performance, and barotrauma under conditions of passive inflation $[28,29]$. In this study, $P_{\text {mean }}$ and Cdyn in the PCV +OLA and VCV+OLA groups were similar, and both were higher than those in the PCV and VCV groups. The reason may be related to the application of higher individualized PEEP. Indeed, others have shown that $P_{\text {mean }}$ was significantly higher in the PCV+PEEP group compared with the VCV +zero PEEP and PCV+zero PEEP groups [24, 30]. Furthermore, it usually requires the application of extrinsic PEEP by increasing $P_{\text {mean }}$ during OLV to prevent hypoventilation and atelectasis caused by low $V_{\mathrm{T}}[31-33]$. As a matter of fact, an abnormally high $P_{\text {mean }}$ may incur the impairment of pulmonary circulation and hemodynamic stability [34]. However, there was no difference in hemodynamics among the four groups, probably because the higher $P_{\text {mean }}$ in the PCV +OLA and VCV+OLA groups did not substantially affect hemodynamic stability during OLV. On the other hand, excessively high $P_{\text {mean }}$, especially mean alveolar pressure, increases pulmonary vascular resistance and makes blood flow towards the nonventilated lung, thus leading to the dis- turbance of Qs/Qt $[29,35,36]$. Nevertheless, the Qs/Qt in the PCV+OLA group was superior to that in the other groups during OLV, suggesting that acceptable $P_{\text {mean }}$ recruits alveoli and tends to keep them properly open.

The higher $\mathrm{PaO}_{2} / \mathrm{FiO}_{2}$ ratio and lower $V_{\mathrm{D}} / V_{\mathrm{T}}$ of the $\mathrm{PCV}$ +OLA and VCV+OLA groups during OLV may have been owing to the impact of the OLA and reasonable $P_{\text {mean }}$ on oxygenation and the prevention of atelectasis. We assumed that the most suitable PEEP might more effectively maintain the advantages of an alveoli recruitment maneuver with regard to ventilation efficiency under the automatic adjustment of PCV-VG mode. Unlike the constant flow pattern observed in VCV, the pattern of inspiratory flow in PCV-VG mode is a deceleration type with high initial flow velocity, which results in compliant alveolar expansion and improves ventilation-perfusion matching [37]. Therefore, the PCV +OLA ventilation strategy integrated the merits of PCV-VG and OLA to improve both gas exchange and oxygenation accordingly. Another explanation was that $\mathrm{FiO}_{2}$ of 0.8 used during OLV could decrease the number of areas suffering from atelectasis and, consequently, lead to lowering Qs/Qt $[35,38]$. However, some studies showed that compared with $\mathrm{VCV}$, no benefits were found in PCV about the length of hospital stay and $\mathrm{PaO}_{2} / \mathrm{FiO}_{2}$ ratio $[26,39]$. Consistent with the negative results of these studies, the results of respiratory mechanics and ventilation efficiency in the PCV group and the VCV group were similar; the reason may be that except for the different ventilator modes, the other treatment measures were the same in these two groups.

The release of pulmonary inflammatory mediators and their cascade reaction during OLV are the major mechanisms resulting in acute lung injury [16]. Neutrophil elastase participates in and initiates acute lung injury by injuring capillary endothelial cells and alveolar epithelial cells, as well as digesting and degrading the extracellular matrix and epithelial junctions [40]. A recent study showed that compared with VCV, PCV-VG could decrease the release of neutrophil elastase and minimize inflammatory reaction to reduce lung injury in patients undergoing OLV [22]. FernandezBustamante et al. proposed that plasma neutrophil elastase might indicate atelectrauma in patients with short-term mechanical ventilation [41]. We found that the plasma concentration of neutrophil elastase was decreased considerably in the PCV+OLA group compared with the PCV, VCV, and VCV+OLA groups after OLV, demonstrating that the strategy of PCV-VG plus OLA had an important influence on alleviating ventilator-induced lung injury.

Unfortunately, except for the shortening of the duration of ICU stay, the prevalence of other postoperative endpoints did not decrease. Whether the strategy of PCV-VG plus OLA can impact upon postoperative duration of hospital stay, total duration of hospital stay, or the incidence of PPCs requires further study at multiple centers.

Our study had two main limitations. First, our study was not blinded, so biases are inevitable. Second, we only observed changes in heart rate and MAP. We intend to determine the effect of PCV-VG plus OLA during OLV on hemodynamic variables by measuring central venous pressure and cardiac output. 


\section{Conclusion}

The ventilation strategy of PCV-VG combined with openlung approach during OLV was associated with favorable effects upon intraoperative respiratory mechanics, oxygenation parameters, and the inflammatory reaction. This ventilation strategy may be a feasible alternative ventilation method in patients undergoing thoracic surgery.

\section{Data Availability}

The clinical data used to support the findings of this study are available from the corresponding author upon reasonable request.

\section{Conflicts of Interest}

No conflict of interest has to be disclosed.

\section{Authors' Contributions}

Jianli Li, MD, and Baogui Cai designed the study, conducted the study, analyzed the data, and approved the final manuscript. Dongdong Yu and Meinv Liu designed the study and wrote the manuscript. Xiaoqian $\mathrm{Wu}$ conducted the study. Junfang Rong, MD, analyzed data and wrote and edited the manuscript. Jianli Li and Baogui Cai contributed equally to this work and should be considered co-first authors.

\section{Acknowledgments}

The authors wish to thank all staff members in the Department of Anesthesiology, Hebei General Hospital, for their help in the study. The study was supported by the Key Research and Development Program of Hebei Province (19277714D).

\section{References}

[1] K. Mahmoud, A. Ammar, and Z. Kasemy, "Comparison between pressure-regulated volume-controlled and volumecontrolled ventilation on oxygenation parameters, airway pressures, and immune modulation during thoracic surgery," Journal of Cardiothoracic and Vascular Anesthesia, vol. 31, no. 5, pp. 1760-1766, 2017.

[2] F. de la Gala, P. Piñeiro, I. Garutti et al., "Systemic and alveolar inflammatory response in the dependent and nondependent lung in patients undergoing lung resection surgery: a prospective observational study," European Journal of Anaesthesiology, vol. 32, no. 12, pp. 872-880, 2015.

[3] A. M. Kaynar, A. M. Houghton, E. H. Lum, B. R. Pitt, and S. D. Shapiro, "Neutrophil elastase is needed for neutrophil emigration into lungs in ventilator-induced lung injury," American Journal of Respiratory Cell and Molecular Biology, vol. 39, no. 1, pp. 53-60, 2008.

[4] M. Park, H. J. Ahn, J. A. Kim et al., "Driving pressure during thoracic surgery: a randomized clinical trial," Anesthesiology, vol. 130, no. 3, pp. 385-393, 2019.

[5] A. Serpa Neto, S. N. Hemmes, C. S. Barbas et al., "Protective versus conventional ventilation for surgery: a systematic review and individual patient data meta-analysis," Anesthesiology, vol. 123, no. 1, pp. 66-78, 2015.

[6] D. Yang, M. C. Grant, A. Stone, C. L. Wu, and E. C. Wick, "A meta-analysis of intraoperative ventilation strategies to prevent pulmonary complications: is low tidal volume alone sufficient to protect healthy lungs?," Annals of Surgery, vol. 263, no. 5, pp. 881-887, 2016.

[7] C. Ferrando, A. Mugarra, A. Gutierrez et al., "Setting individualized positive end-expiratory pressure level with a positive end-expiratory pressure decrement trial after a recruitment maneuver improves oxygenation and lung mechanics during one-lung ventilation," Anesthesia and Analgesia, vol. 118, no. 3, pp. 657-665, 2014.

[8] C. Ferrando, F. Suarez-Sipmann, G. Tusman et al., "Open lung approach versus standard protective strategies: effects on driving pressure and ventilatory efficiency during anesthesia - a pilot, randomized controlled trial," PLoS One, vol. 12, no. 5, 2017.

[9] M. Lian, X. Zhao, H. Wang, L. Chen, and S. Li, "Respiratory dynamics and dead space to tidal volume ratio of volumecontrolled versus pressure-controlled ventilation during prolonged gynecological laparoscopic surgery," Surgical Endoscopy, vol. 31, no. 9, pp. 3605-3613, 2017.

[10] J. Tan, Z. Song, Q. Bian, P. Li, and L. Gu, "Effects of volumecontrolled ventilation $v s$. pressure-controlled ventilation on respiratory function and inflammatory factors in patients undergoing video-assisted thoracoscopic radical resection of pulmonary carcinoma," Journal of Thoracic Disease, vol. 10, no. 3, pp. 1483-1489, 2018.

[11] A. Bagchi, M. I. Rudolph, P. Y. Ng et al., "The association of postoperative pulmonary complications in 109,360 patients with pressure-controlled or volume-controlled ventilation," Anaesthesia, vol. 72, no. 11, pp. 1334-1343, 2017.

[12] Y. Maeda, Y. Fujino, A. Uchiyama, N. Matsuura, T. Mashimo, and M. Nishimura, "Effects of peak inspiratory flow on development of ventilator-induced lung injury in rabbits," Anesthesiology, vol. 101, no. 3, pp. 722-728, 2004.

[13] F. Lin, L. Pan, W. Qian, W. Ge, H. Dai, and Y. Liang, "Comparison of three ventilatory modes during one-lung ventilation in elderly patients," International Journal of Clinical and Experimental Medicine, vol. 8, no. 6, pp. 9955-9960, 2015.

[14] M. Gad, K. Gaballa, A. Abdallah, M. Abdelkhalek, A. Zayed, and H. Nabil, "Pressure-controlled ventilation with volume guarantee compared to volume-controlled ventilation with equal ratio in obese patients undergoing laparoscopic hysterectomy," Anesthesia, Essays and Researches, vol. 13, no. 2, pp. 347-353, 2019.

[15] D. Amar, H. Zhang, A. Pedoto, D. P. Desiderio, W. Shi, and K. S. Tan, "Protective lung ventilation and morbidity after pulmonary resection: a propensity score-matched analysis," Anesthesia and Analgesia, vol. 125, no. 1, pp. 190-199, 2017.

[16] J. Lohser and P. Slinger, "Lung injury after one-lung ventilation: a review of the pathophysiologic mechanisms affecting the ventilated and the collapsed lung," Anesthesia and Analgesia, vol. 121, no. 2, pp. 302-318, 2015.

[17] Y. Sugasawa, K. Yamaguchi, S. Kumakura et al., "The effect of one-lung ventilation upon pulmonary inflammatory responses during lung resection," Journal of Anesthesia, vol. 25, no. 2, pp. 170-177, 2011.

[18] K. Takenaka, E. Ogawa, H. Wada, and T. Hirata, "Systemic inflammatory response syndrome and surgical stress in 
thoracic surgery," Journal of Critical Care, vol. 21, no. 1, pp. 48-53, 2006.

[19] A. Güldner, T. Kiss, A. Serpa Neto et al., "Intraoperative protective mechanical ventilation for prevention of postoperative pulmonary complications: a comprehensive review of the role of tidal volume, positive end-expiratory pressure, and lung recruitment maneuvers," Anesthesiology, vol. 123, no. 3, pp. 692-713, 2015.

[20] S. M. Pereira, M. R. Tucci, C. C. A. Morais et al., "Individual positive end-expiratory pressure settings optimize intraoperative mechanical ventilation and reduce postoperative atelectasis," Anesthesiology, vol. 129, no. 6, pp. 1070-1081, 2018.

[21] C. Ferrando, M. Soro, C. Unzueta et al., "Individualised perioperative open-lung approach versus standard protective ventilation in abdominal surgery (iPROVE): a randomised controlled trial," The Lancet Respiratory Medicine, vol. 6, no. 3, pp. 193-203, 2018.

[22] W. Yao, M. Yang, Q. Cheng et al., "Effect of pressurecontrolled ventilation-volume guaranteed on one-lung ventilation in elderly patients undergoing thoracotomy," Medical Science Monitor, vol. 26, 2020.

[23] S. H. Byun, S. Y. Lee, and J. Y. Jung, "Effects of small tidal volume and positive end-expiratory pressure on oxygenation in pressure-controlled ventilation-volume guaranteed mode during one-lung ventilation," Yeungnam University Journal of Medicine, vol. 35, no. 2, pp. 165-170, 2018.

[24] J. M. Dion, C. McKee, J. D. Tobias et al., "Ventilation during laparoscopic-assisted bariatric surgery: volume-controlled, pressure-controlled or volume-guaranteed pressure-regulated modes," International Journal of Clinical and Experimental Medicine, vol. 7, no. 8, pp. 2242-2247, 2014.

[25] S. Y. Song, J. Y. Jung, M. S. Cho, J. H. Kim, T. H. Ryu, and B. I. Kim, "Volume-controlled versus pressure-controlled ventilation-volume guaranteed mode during one-lung ventilation," Korean Journal of Anesthesiology, vol. 67, no. 4, pp. 258-263, 2014.

[26] H. Rozé, M. Lafargue, H. Batoz et al., "Pressure-controlled ventilation and intrabronchial pressure during one-lung ventilation," British Journal of Anaesthesia, vol. 105, no. 3, pp. 377$381,2010$.

[27] P. D. Slinger and L. Lesiuk, "Flow resistances of disposable double-lumen, single-lumen, and Univent tubes," Journal of Cardiothoracic and Vascular Anesthesia, vol. 12, no. 2, pp. 142-144, 1998.

[28] A. Bunnell and M. L. Cheatham, "Airway pressures as surrogate estimates of intra-abdominal pressure," The American Surgeon, vol. 81, no. 1, pp. 81-85, 2015.

[29] J. J. Marini and S. A. Ravenscraft, "Mean airway pressure: physiologic determinants and clinical importance-part 2: clinical implications," Critical Care Medicine, vol. 20, no. 11, pp. 1604-1616, 1992.

[30] Y. S. Choi, M. K. Bae, S. H. Kim, J. E. Park, S. Y. Kim, and Y. J. Oh, "Effects of alveolar recruitment and positive endexpiratory pressure on oxygenation during one-lung ventilation in the supine position," Yonsei Medical Journal, vol. 56, no. 5, pp. 1421-1427, 2015.

[31] T. J. Gal, "Con: low tidal volumes are indicated during onelung ventilation," Anesthesia and Analgesia, vol. 103, no. 2, pp. 271-273, 2006.

[32] V. Fanelli, M. V. Ranieri, J. Mancebo et al., "Feasibility and safety of low-flow extracorporeal carbon dioxide removal to facilitate ultra-protective ventilation in patients with moderate acute respiratory distress syndrome," Critical Care, vol. 20, no. 1, 2016.

[33] L. Gattinoni, "Ultra-protective ventilation and hypoxemia," Critical Care, vol. 20, no. 1, p. 130, 2016.

[34] X. Repessé, C. Charron, and A. Vieillard-Baron, "Acute cor pulmonale in ARDS: rationale for protecting the right ventricle," Chest, vol. 147, no. 1, pp. 259-265, 2015.

[35] M. Sentürk, "New concepts of the management of one-lung ventilation," Current Opinion in Anaesthesiology, vol. 19, no. 1, pp. 1-4, 2006.

[36] T. J. Gallagher and M. J. Banner, "Mean airway pressure as A determinant of oxygenation," Critical Care Medicine, vol. 8, no. 4, p. 244, 1980.

[37] M. Prella, F. Feihl, and G. Domenighetti, "Effects of short-term pressure-controlled ventilation on gas exchange, airway pressures, and gas distribution in patients with acute lung injury/ARDS: comparison with volume-controlled ventilation," Chest, vol. 122, no. 4, pp. 1382-1388, 2002.

[38] L. Edmark, K. Kostova-Aherdan, M. Enlund, and G. Hedenstierna, "Optimal oxygen concentration during induction of general anesthesia," Anesthesiology, vol. 98, no. 1, pp. 28-33, 2003.

[39] Z. Liu, X. Liu, Y. Huang, and J. Zhao, "Intraoperative mechanical ventilation strategies in patients undergoing one-lung ventilation: a meta-analysis," Springerplus, vol. 5, no. 1, p. 1251, 2016.

[40] T. Kodama, H. Yukioka, T. Kato, N. Kato, F. Hato, and S. Kitagawa, "Neutrophil elastase as a predicting factor for development of acute lung injury," Internal medicine, vol. 46, no. 11, pp. 699-704, 2007.

[41] A. Fernandez-Bustamante, J. Klawitter, J. E. Repine et al., "Early effect of tidal volume on lung injury biomarkers in surgical patients with healthy lungs," Anesthesiology, vol. 121, no. 3, pp. 469-481, 2014. 